\title{
An Investigation on Dislocation Density in Cold-Rolled Copper Using Electrochemical Impedance Spectroscopy
}

\author{
Elyas Rafiee, ${ }^{1}$ Mansour Farzam, ${ }^{1}$ Mohammad Ali Golozar, ${ }^{2}$ and Ali Ashrafi ${ }^{3}$ \\ ${ }^{1}$ Technical Inspection Engineering Department, Petroleum University of Technology, Abadan, Iran \\ ${ }^{2}$ Department of Materials Engineering, Isfahan University of Technology, Isfahan 8415683111, Iran \\ ${ }^{3}$ Department of Materials Science and Engineering, Shahid Chamran University of Ahvaz, Iran
}

Correspondence should be addressed to Mansour Farzam; farzam@put.ac.ir

Received 7 February 2013; Accepted 1 March 2013

Academic Editors: C.-H. Hsu and S. J. Lee

Copyright (C) 2013 Elyas Rafiee et al. This is an open access article distributed under the Creative Commons Attribution License, which permits unrestricted use, distribution, and reproduction in any medium, provided the original work is properly cited.

\begin{abstract}
Variation of electrochemical impedance with dislocation density was investigated using electrochemical impedance spectroscopy (EIS). For this purpose, EIS measurements were carried out on 10, 20, 30, 40, and 50\% cold-rolled commercially pure copper in $0.1 \mathrm{M} \mathrm{NaCl}(\mathrm{pH}=2)$ solution. Nyquist plots illustrated that the electrochemical reactions are controlled by both charge transfer and diffusion process. Increasing dislocation density, the magnitude of electrochemical impedance of samples was decreased. Decreasing magnitude of impedance at intermediate frequencies indicated increasing double-layer capacitance. Charge transfer resistance decreased from value $329.6 \Omega \mathrm{cm}^{2}$ for annealed sample to $186.3 \Omega \mathrm{cm}^{2}$ for sample with maximum dislocation density $\left(1.72 \times 10^{15} \mathrm{~m}^{-2}\right)$. Phase angles were lower for samples that contained more dislocation density, indicating more tendencies to loss of electrons and releasing atoms into electrolyte.
\end{abstract}

\section{Introduction}

It has been reported that after deformation of a metal more than yield limit, hardening occurs which is due to multiplication and rearrangement of dislocations and the more severe the cold deformation, the more generation of dislocations [1-4].

Tensile properties of metals such as yield strength, ultimate tensile strength, and ductility depend heavily on density of dislocations. Also, dislocation density plays a significant role on brittle to ductile transition, fatigue, hardness, work hardening, and plastic behavior of metals and alloys [58]. Furthermore, dislocations have considerable effect on physical properties of metals such as density [9-12], thermal conductivity $[13,14]$, and electrical resistivity $[9,13,14]$.

In this respect, some researchers $[5,15,16]$ have investigated density of dislocations by ultrasound waves and have proposed some relationships between dislocation density and changes in the speed of elastic waves propagation. Sablik and Landgraf [17, 18], Kobayashi et al. [19], and Yaegashi [20] reported some relationships between dislocation density and magnetic properties. Kikuchi et al. [21] investigated the relation between AC permeability and dislocation density in pure iron as well. Also, other researchers tried to correlate dislocation density with stored energy and critical transformation temperatures using differential scanning calorimetry $[4,7,22]$ and high-resolution dilatometry [23], respectively.

The strain field and energy of dislocation line intersects with metal surface increase the susceptibility of the metal to corrosion [24-26]. Since corrosion is an electrochemical degradation, electrochemical techniques can be utilized for studying the corrosion process. Electrochemical impedance spectroscopy (EIS) is one of the most useful, nondestructive, sensitive, powerful, and fastest electrochemical characterization techniques presently available [27-29] and is becoming a beloved analytical instrument in evaluation of electrical properties and interfaces of a wide range of materials. This technique includes a comparatively simple electrical measurements that can easily be automated, and its results become correlated with many complex materials variables [30-32]. Therefore, it seems that it can be used for studying the variation of dislocations density in a metal. Having this 
in mind, the aim of this work is to investigate the effect of dislocation density on electrochemical impedance in coldrolled copper using EIS.

\section{Experimental}

In order to prepare samples with different dislocation densities to perform electrochemical measurements, commercially pure $(99.98 \%)$ copper strips were annealed at $500^{\circ} \mathrm{C}$ for $2 \mathrm{~h}$, to remove residual stresses and obtain a recrystallized microstructure having the lowest dislocation density, followed by cold rolling at ambient temperature to obtain 10, 20, 30,40 , and $50 \%$ reductions in area.

Tensile tests were carried out on cold-rolled strips to determine the yield stresses of samples. In this regard, standard tensile specimens were cut from strips according to ASTM E8-04 with gauge length of $50 \mathrm{~mm}$. Tensile tests were performed using a constant strain rate of $2 \times 10^{-3} \mathrm{~s}^{-1}$.

Samples for electrochemical tests were cut from crosssection of rolled strips. In order to avoid further deformation during cutting, samples were cut using electrodischarge machining (EDM) method. Samples and connecting copper wire were coated by Epoxy resin as to expose only one side of samples to solution. All samples were mechanically polished with silicon carbide abrasive paper down to 2000 grade, and then $0.05 \mu \mathrm{m} \mathrm{Al} \mathrm{O}_{3}$ slurry was used to get mirror-like finished surfaces. Finally, samples were ultrasonically washed in ethanol. This treatment ensures good reproducibility of electrochemical measurements. These specimens were used as working electrode in the EIS tests. The EIS measurements were done using potentiostat/galvanostat autolab.

To achieve the steady state open-circuit potential, specimens were immersed in the solution for $20 \mathrm{~min}$. Impedance measurements were made at open-circuit potential using a sinusoidal signal of $10 \mathrm{mV}$ amplitude and frequencies in the range of $0.01 \mathrm{~Hz}$ to $100 \mathrm{kHz}$ in a conventional three-electrode glass cell containing an $\mathrm{Ag} / \mathrm{AgCl}$ reference electrode and $\mathrm{Pt}$ counter electrode. All tests were performed in $0.1 \mathrm{M} \mathrm{NaCl}$ solution at room temperature and $\mathrm{pH}$ value of 2 . At least three EIS tests were carried out for each sample.

\section{Results and Discussion}

Figure 1 shows stress-strain curves of cold-rolled specimens. Dislocation multiplication and their interactions lead to increasing ultimate tensile strength, yield strength and decreasing ductility as plastic deformation increases.

Yield strength and true strain values of cold-rolled samples are listed in Table 1. As it can be seen, yield strength has increased by cold working.

Empirical data achieved by numerous metals and alloys suggests that the yield stress of a metal is related to the total dislocation density by

$$
\sigma=\sigma_{0}+M \alpha G b \rho^{1 / 2},
$$

where $\alpha$ is a constant, $M$ average Taylor factor, $\sigma_{0}$ is friction stress that for FCC metals is equal to zero, $G$ is the shear modulus, $b$ is the length of Burgers vector, and $\rho$ is the
TABLE 1: Yield strength and true strain corresponding to each amount of cold work.

\begin{tabular}{lcccccc}
\hline Specimen code & C10 & C9 & C8 & C7 & C6 & C5 \\
\hline Cold work (\%) & 0 & 10 & 20 & 30 & 40 & 50 \\
True strain & 0 & 0.09 & 0.18 & 0.26 & 0.34 & 0.40 \\
Yield strength & 162.54 & 221.88 & 255.15 & 275.33 & 290.52 & 292.31 \\
\begin{tabular}{l}
$(0.2 \%)(\mathrm{MPa})$ \\
\hline
\end{tabular} & & & & & & \\
\hline
\end{tabular}

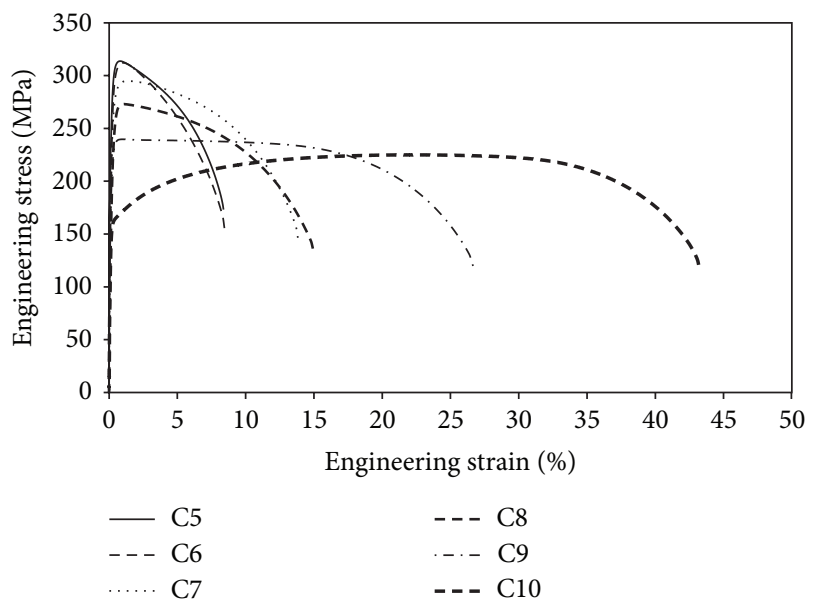

FIGURE 1: Stress-strain curves of cold rolled samples.

measured dislocation density [7, 12, 33-35]. This relation has some theoretical bases and has been proved in many experimental works performed on metals and alloys [33].

Employing yield stress values obtained from stress-strain curves and the Taylor factor $M=3.06, \sigma_{0}=0$ for FCC metals, $\alpha=0.2, G=46 \mathrm{GPa}$, and $b=2.5 \times 10^{-10} \mathrm{~m}$ for copper [36], dislocation densities corresponding to each deformation in this work were calculated (Table 2). Results were in a good agreement with former works by other researchers, for example [37]. As it can be seen, by increasing deformation, dislocation density is increased from $5.33 \times 10^{14} \mathrm{~m}^{-2}$ for annealed specimen to $1.72 \times 10^{15} \mathrm{~m}^{-2}$ for maximum deformed specimen (true strain $=0.4$ ).

Cold working is capable of affecting not only the mechanical properties of metals, but also their corrosion behavior. However, there is not a clarified correlation between cold working and corrosion properties because the cold working influences differently the corrosion resistance depending on metal, deformation, and environment [38].

Figure 2 shows Nyquist plots of deformed samples after 20 min immersion in $0.1 \mathrm{M}$ sodium chloride solution $(\mathrm{pH}=$ 2) at $25^{\circ} \mathrm{C}$. These impedance diagrams indicate a depressed capacitive semicircle and diffusion line for all samples. Depressed capacitive semicircles describe the charge transfer reaction occurring during copper dissolution at corrosion potential. In electrochemical systems, the depressed semicircles in Nyquist diagram have been ascribed to the roughness of surface, the existence of a porous corrosion product film, or the inhomogeneous nature of the surface $[31,32,39,40]$. 
TABLE 2: Dislocation densities corresponding to each deformation in this work.

\begin{tabular}{lcccccc}
\hline Specimen code & C10 & C9 & C8 & C7 & C6 & C5 \\
\hline Dislocation density $\left(\mathrm{m}^{-2}\right)$ & $5.33 \times 10^{14}$ & $9.94 \times 10^{14}$ & $1.31 \times 10^{15}$ & $1.51 \times 10^{15}$ & $1.7 \times 10^{15}$ & $1.72 \times 10^{15}$ \\
\hline
\end{tabular}

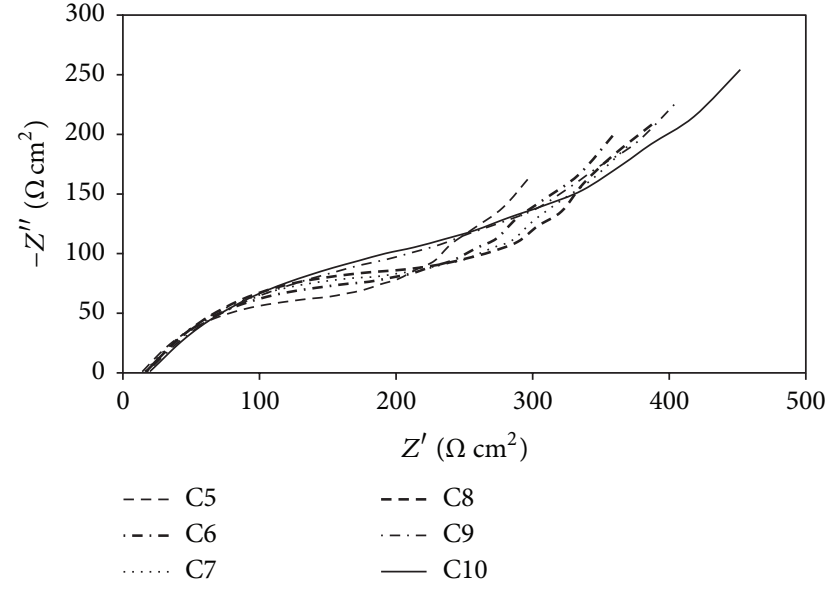

FIGURE 2: Nyquist plots of deformed samples.

Diameter of the semicircles indicates charge transfer resistance. It can be seen that the diameter of the semicircles varies with the dislocation density of the samples and decreases by increasing dislocation density.

Corrosion of copper in $\mathrm{NaCl}$ solutions having low chloride concentrations occurs through the formation of $\mathrm{CuCl}$ which is not protective and is converted to $\mathrm{CuCl}_{2}{ }^{-}$by reacting with chloride ions. In this condition, $\mathrm{CuCl}_{2}{ }^{-}$is created at the metal surface and then diffuses into the bulk solution [41-43]. Reactions are as follows:

$$
\begin{gathered}
\mathrm{Cu} \longrightarrow \mathrm{Cu}^{+}+\mathrm{e}^{-} \\
\mathrm{Cu}^{+}+\mathrm{Cl}^{-} \longrightarrow \mathrm{CuCl}_{\mathrm{ads}} \\
\mathrm{CuCl}_{\mathrm{ads}}+\mathrm{Cl}^{-} \longrightarrow \mathrm{CuCl}_{2}^{-}
\end{gathered}
$$

The cathodic reactions in this environment are oxygen and $\mathrm{H}^{+}$reduction according to

$$
\begin{gathered}
\mathrm{O}_{2}+4 \mathrm{H}^{+}+4 e^{-} \longrightarrow 2 \mathrm{H}_{2} \mathrm{O} \\
2 \mathrm{H}^{+}+2 e^{-} \longrightarrow \mathrm{H}_{2}
\end{gathered}
$$

Here the semicircles are followed by a diffusion line at lower frequencies attributed to the diffusion of species to or from metal surface and illustrate that the electrochemical reactions are controlled by both charge transfer and diffusion process. According to the previous equations, corrosion of copper will depend on the movement of $\mathrm{O}_{2}, \mathrm{H}^{+}, \mathrm{CuCl}_{2}{ }^{-}$, and $\mathrm{Cu}^{+}$to and from metal/solution interface. On the base of mixed potential theory, enhanced movement of $\mathrm{Cl}^{-}$or $\mathrm{CuCl}_{2}{ }^{-}$, to or from the electrode surface, will increase the anodic reaction rate, while enhancement of $\mathrm{O}_{2}$ and $\mathrm{H}^{+}$ movement will accelerate the cathodic reaction rate; therefore corrosion rate, will increase. However, it has been reported

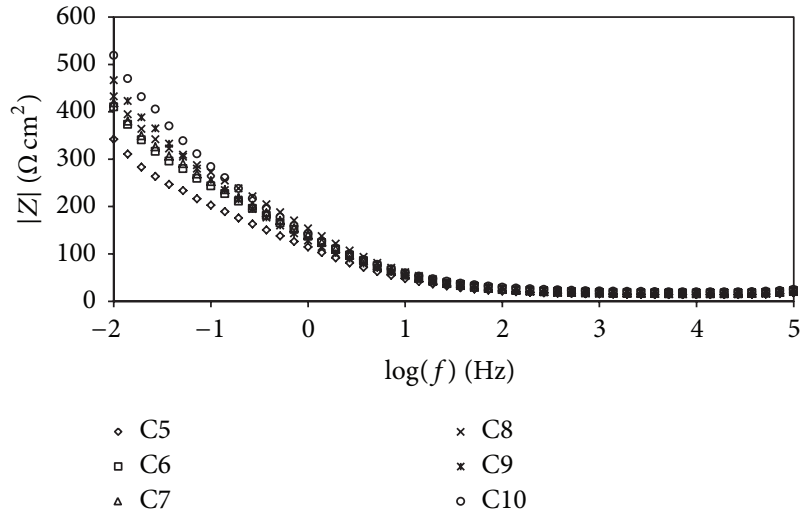

FIGURE 3: Bode diagram of samples.

that mostly transport of $\mathrm{CuCl}_{2}{ }^{-}$from metal surface to the bulk solution controls the corrosion rate [41, 44-46].

Bode diagrams of samples are plotted in Figure 3. Although the differences created are small, increasing dislocation density, the impedance magnitude of samples surface is decreased. The Bode plots show resistive region at high frequencies and capacitive region at intermediate frequencies but do not show a clear resistive region (horizontal line) at low frequencies. This strict descending behavior at low frequencies is due to Warburg impedance.

As mentioned previous, the magnitude of impedance in bode plot at intermediate frequencies is related to capacitive behavior of electrochemical system, and as seen, this value decreases by increasing deformation. Since this value of impedance is proportional to reciprocal of capacitance $(Z \propto$ $1 / C)$, therefore double-layer capacitance will increase by increasing dislocation density. The double-layer capacitance is calculated by

$$
C=\varepsilon_{0} \varepsilon \frac{A}{d},
$$

where $\varepsilon_{0}$ is the vacuum permittivity, $\varepsilon$ is the dielectric constant of the medium, $A$ is area of the electrode surface, and $d$ is thickness of double layers. Thus, since for all samples $\varepsilon_{0}$ and $\varepsilon$ are constant and impact of surface areas was applied, increase of capacitance is due to the decrease of double-layer thickness.

Bode-phase plots of samples shown in Figure 4 are used for investigating the variations of phase angle and time constants with plastic deformation. All of these diagrams show two time constants, one at low frequencies that belongs to $\mathrm{CuCl}$ film and the other at higher frequencies referring to double layers. No changes in general shape of curves with increasing dislocation density show identical reaction mechanisms for all samples. 


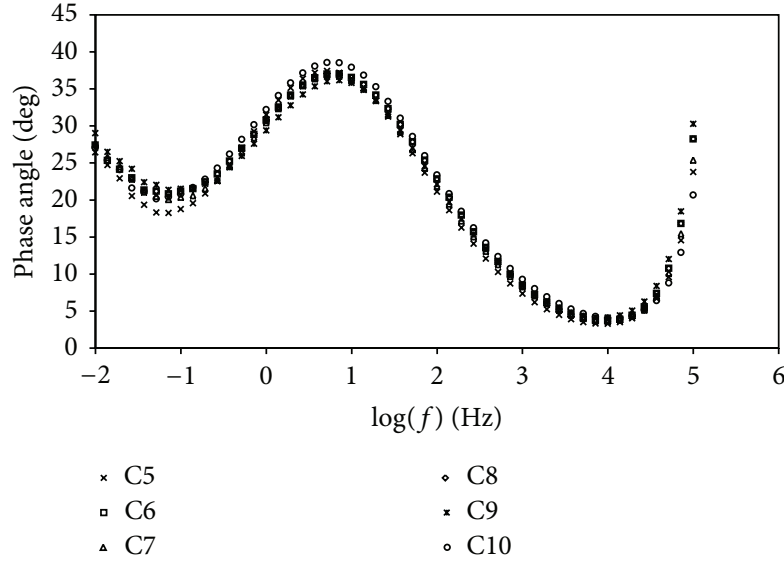

FIgURE 4: Bode-phase plots of samples.

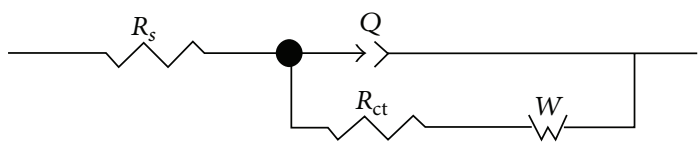

FIGURE 5: Used equivalent circuit for fitting experimental data.

As it is seen in bode-phase plots, generally, the more dislocation density the lower phase angle. Increasing surface energy of metal induced by dislocations, the tendency to loss of electrons and releasing atoms into electrolyte accelerates. Therefore after polarizing by a signal in EIS test, it is expected that current response in sample with higher dislocation density be faster, hence, phase angle at a constant frequency be lower.

A significant trouble for impedance spectroscopy at high frequencies is the parasitic segments and the phase angles linked to the potentiostatic control of the system [31]; therefore this behavior of some points at high frequencies is attributed to this fact.

Using equivalent circuit shown in Figure 5, the values of equivalent circuit parameters calculated by fitting of impedance spectra of samples are listed in Table 3. In this equivalent electrical circuit (EEC), $R_{s}$ is the solution resistance, $Q$ represents the capacitance of the double layers, $R_{\mathrm{ct}}$ the charge transfer resistance, and $W$ is the Warburg impedance.

Use of Constant Phase Element (CPE) instead of pure capacitance ( $Q$ in the EEC) is due to making a good fitting. Constant phase element indicates the nonideal capacitive behavior of the electrochemical system because on the microscopic view, electrode surface is rough and inhomogeneous [30].

As exhibited in Table 3, the charge transfer resistance $R_{\mathrm{ct}}$ decreases while the Warburg impedance $W$ increases with increasing cold work. Thus, it can be concluded that the corrosion rate and the movement of ions within the corrosion product increase with increasing deformation. Decrease of charge transfer resistance with straining is chiefly ascribed to a higher migration of atoms from active sites in this environment.
TABLE 3: Values of equivalent circuit parameters calculated by fitting.

\begin{tabular}{lccccc}
\hline Sample & $\begin{array}{c}R_{s} \\
\left(\Omega \mathrm{cm}^{2}\right)\end{array}$ & $\begin{array}{c}Y_{0} \\
\left(\mathrm{~s}^{n} / \Omega \mathrm{cm}^{2}\right)\end{array}$ & $n$ & $\begin{array}{c}R_{\mathrm{ct}} \\
\left(\Omega \mathrm{cm}^{2}\right)\end{array}$ & $\begin{array}{c}W \\
\left(\mathrm{~s}^{1 / 2} / \Omega \mathrm{cm}^{2}\right)\end{array}$ \\
\hline C10 & 18.98 & 0.002002 & 0.8 & 329.6 & 0.01104 \\
C9 & 17.09 & 0.002221 & 0.8 & 296.1 & 0.01227 \\
C8 & 16.54 & 0.001491 & 0.8 & 260 & 0.01459 \\
C7 & 15.49 & 0.001598 & 0.8 & 243.7 & 0.01577 \\
C6 & 16.4 & 0.001579 & 0.8 & 223.5 & 0.01505 \\
C5 & 13.67 & 0.001895 & 0.8 & 186.3 & 0.01806 \\
\hline
\end{tabular}

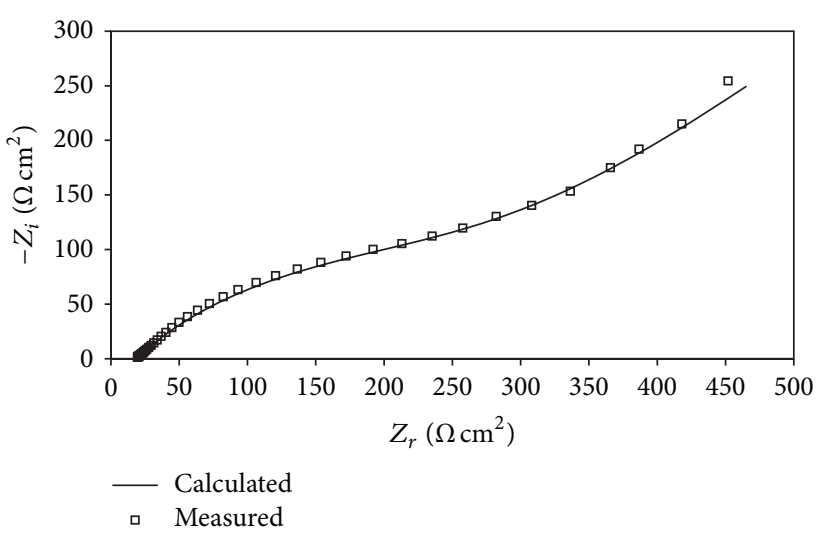

FIGURE 6: Good agreement between the experimental and simulated data generated using the circuit.

Since dislocations enhance atomic migration, plastic deformation may promote and accelerate formation of surface $\mathrm{CuCl}$ film. As regards charge transfer resistance $R_{\mathrm{ct}}$ continuously decreasing with increasing deformation, it can be concluded that $\mathrm{CuCl}$ film formed on electrode surface does not have enough adhesion and compactness to protect the metal and is not able to prevent further dissolution of surface atoms of metal what has been reported by other researchers [41-43].

In Figure 6, white squares represent the measured data and solid line represents the best fit using the equivalent circuit shown in Figure 5. It can be seen that there is a very good agreement between the experimental and simulated data generated using the EEC, indicating the validity of proposed EEC.

\section{Conclusions}

(1) Electrochemical impedance spectroscopy at corrosion potential is very sensitive to variation of electrochemical activity induced by dislocations.

(2) Semicircles in Nyquist plots are followed by a diffusion line at lower frequencies that illustrates that the electrochemical reactions are controlled by both charge transfer and diffusion process.

(3) Charge transfer resistance of samples decreases with increasing dislocation density. 
(4) Decreasing the magnitude of impedance at intermediate frequencies by increasing dislocation density indicates decrease of the double-layer thickness.

(5) Bode-phase diagrams show two time constants and identical reaction mechanism for all samples.

(6) Increasing dislocation density leads to decreasing phase angle, indicating more tendencies to loss of electrons and releasing atoms into electrolyte.

\section{Acknowledgments}

This work has been done under the financial support of the National Iranian Drilling Company (NIDC). The authors are grateful to Engineer Darbandi and R\&D center of NIDC.

\section{References}

[1] S. C. Wang, Z. Zhu, and M. J. Starink, "Estimation of dislocation densities in cold rolled $\mathrm{Al}-\mathrm{Mg}-\mathrm{Cu}-\mathrm{Mn}$ alloys by combination of yield strength data, EBSD and strength models," Journal of Microscopy, vol. 217, no. 2, pp. 174-178, 2005.

[2] A. Čiuplys, J. Vilys, V. Čiuplys, and V. Kvedaras, "Investigation of dislocation structure of low carbon steel during static loading," Mechanika, vol. 4, pp. 59-66, 2006.

[3] H. D. Chandler, "Work hardening characteristics of copper from constant strain rate and stress relaxation testing," Materials Science and Engineering A, vol. 506, no. 1-2, pp. 130-134, 2009.

[4] M. Kazeminezhad, "Relationship between the stored energy and indentation hardness of copper after compression test: models and measurements," Journal of Materials Science, vol. 43, no. 10, pp. 3500-3504, 2008.

[5] A. Maurel, V. Pagneux, F. Barra, and F. Lund, "Ultrasound as a probe of plasticity? The interaction of elastic waves with dislocations," International Journal of Bifurcation and Chaos, vol. 19, no. 8, pp. 2765-2781, 2009.

[6] Y. B. Wang, J. C. Ho, Y. Cao et al., "Dislocation density evolution during high pressure torsion of a nanocrystalline Ni-Fe alloy," Applied Physics Letters, vol. 94, Article ID 091911, 3 pages, 2009.

[7] M. Verdier, I. Groma, L. Flandin, J. Lendvai, Y. Bréchet, and P. Guyot, "Dislocation densities and stored energy after cold rolling of Al-Mg alloys: investigations by resistivity and differential scanning calorimetry," Scripta Materialia, vol. 37, no. 4, pp. 449-454, 1997.

[8] S. Graça, R. Colaço, P. A. Carvalho, and R. Vilar, "Determination of dislocation density from hardness measurements in metals," Materials Letters, vol. 62, pp. 3812-3814, 2008.

[9] G. E. Dieter and D. Bacon, Mechanical Metallurgy, McGrawHill, Singapore, 1988.

[10] F. Garofalo and H. A. Wriedt, "Density change in an austenitic stainless steel deformed in tension or compression," Acta Metallurgica, vol. 10, no. 11, pp. 1007-1012, 1962.

[11] R. E. Smallman and R. J. Bishop, Modern Physical Metallurgy and Materials Engineering, Elsevier Science, 1999.

[12] R. E. Smallman and A. H. W. Ngan, Physical Metallurgy and Advanced Materials, Elsevier, Burlington, Vt, USA, 2007.

[13] D. B. Sirdeshmukh, L. Sirdeshmukh, and K. G. Subhadra, Atomistic Properties of Solids, Springer, New York, NY, USA, 2011.

[14] F. Khodabakhshi and M. Kazeminezhad, "The effect of constrained groove pressing on grain size, dislocation density and electrical resistivity of low carbon steel," Materials and Design, vol. 32, no. 6, pp. 3280-3286, 2011.

[15] N. Mujica, M. A. T. Cerda, R. Espinoza, J. Lisoni, and F. Lund, "Ultrasound as a probe of dislocation density in aluminum," Acta Materialia, vol. 60, pp. 5828-5837, 2012.

[16] F. Barra, A. Caru, M. T. Cerda et al., "Measuring dislocation density in aluminum with resonant ultrasound spectroscopy," International Journal of Bifurcation and Chaos, vol. 19, no. 10, pp. 3561-3565, 2009.

[17] M. J. Sablik, "Modeling the effect of grain size and dislocation density on hysteretic magnetic properties in steels," Journal of Applied Physics, vol. 89, no. 10, pp. 5610-5613, 2001.

[18] M. J. Sablik and F. J. G. Landgraf, "Modeling microstructural effects on hysteresis loops with the same maximum flux density," IEEE Transactions on Magnetics, vol. 39, no. 5, pp. 2528-2530, 2003.

[19] S. Kobayashi, T. Kimura, S. Takahashi, Y. Kamada, and H. Kikuchi, "Quantitative evaluation of dislocation density using minor-loop scaling relations," Journal of Magnetism and Magnetic Materials, vol. 320, no. 20, pp. e551-e555, 2008.

[20] K. Yaegashi, "Dependence of magnetic susceptibility on dislocation density in tensile deformed iron and Mn-steel," ISIJ International, vol. 47, no. 2, pp. 327-332, 2007.

[21] H. Kikuchi, Y. Henmi, T. Liu et al., "The relation between AC permeability and dislocation density and grain size in pure iron," International Journal of Applied Electromagnetics and Mechanics, vol. 25, no. 1-4, pp. 341-346, 2007.

[22] A. Karimi Taheri, Kazeminezhad, and A. Kiet Tieu, "theoretical and experimental evaluation of dislocation density in a workpiece after forming," Iranian Journal of Materials Science \& Engineering, vol. 4, pp. 1-8, 2007.

[23] C. Garcia-Mateo, F. G. Caballero, C. Capdevila, and C. G. D. Andres, "Estimation of dislocation density in bainitic microstructures using high-resolution dilatometry", Scripta Materialia, vol. 61, no. 9, pp. 855-858, 2009.

[24] H. Miyamoto, K. Harada, T. Mimaki, A. Vinogradov, and S. Hashimoto, "Corrosion of ultra-fine grained copper fabricated by equal-channel angular pressing," Corrosion Science, vol. 50, no. 5, pp. 1215-1220, 2008.

[25] W. Li and D. Y. Li, "Variations of work function and corrosion behaviors of deformed copper surfaces," Applied Surface Science, vol. 240, no. 1-4, pp. 388-395, 2005.

[26] S. Yin and D. Y. Li, "Effects of prior cold work on corrosion and corrosive wear of copper in $\mathrm{HNO}_{3}$ and $\mathrm{NaCl}$ solutions," Materials Science and Engineering A, vol. 394, no. 1-2, pp. 266276, 2005.

[27] R. G. Kelly, J. R. Scully, D. W. Shoesmith, and R. G. Buchheit, Electrochemical Techniques in Corrosion Science and Engineering, Marcel Dekker, 2002.

[28] A. S. Hamdy, E. El-Shenawy, and T. El-Bitar, "Electrochemical impedance spectroscopy study of the corrosion behavior of some niobium bearing stainless steels in $3.5 \% \mathrm{NaCl}$," International Journal of Electrochemical Science, vol. 1, pp. 171-180, 2006.

[29] N. D. Cogger, An Introduction to Electrochemical Impedance Measurement, Solartron Analytical, 1999.

[30] E. Barsoukov and J. R. Macdonald, Impedance Spectroscopy: Theory, Experiment, and Applications, John Wiley \& Sons, 2005.

[31] F. Scholz, Electroanalytical Methods: Guide to Experiments and Applications, Springer, 2010. 
[32] X. Z. Yuan, C. Song, H. Wang, and J. Zhang, Electrochemical Impedance Spectroscopy in PEM Fuel Cells: Fundamentals and Applications, Springer, 2009.

[33] F. Barlat, M. V. Glazov, J. C. Brem, and D. J. Lege, "A simple model for dislocation behavior, strain and strain rate hardening evolution in deforming aluminum alloys," International Journal of Plasticity, vol. 18, no. 7, pp. 919-939, 2002.

[34] R. Abbaschian, R. E. Reed-Hill, and L. Abbaschian, Physical Metallurgy Principles, Cengage Learning, Stamford, Conn, USA, 2009.

[35] E. Hosseini and M. Kazeminezhad, "Dislocation structure and strength evolution of heavily deformed tantalum," International Journal of Refractory Metals and Hard Materials, vol. 27, no. 3, pp. 605-610, 2009.

[36] W. D. Callister, Materials Science and Engineering: An Introduction, John Wiley \& Sons, New York, NY, USA, 2007.

[37] E. Schafler, M. Zehetbauer, and T. Ungàr, "Measurement of screw and edge dislocation density by means of X-ray Bragg profile analysis," Materials Science and Engineering A, vol. 319321, pp. 220-223, 2001.

[38] A. Robin, G. A. S. Martinez, and P. A. Suzuki, "Effect of coldworking process on corrosion behavior of copper," Materials \& Design, vol. 34, pp. 319-324, 2012.

[39] C. Fonseca and M. A. Barbosa, "Corrosion behaviour of titanium in biofluids containing $\mathrm{H}_{2} \mathrm{O}_{2}$ studied by electrochemical impedance spectroscopy," Corrosion Science, vol. 43, no. 3, pp. 547-559, 2001.

[40] C. L. Zeng, W. Wang, and W. T. Wu, "Electrochemical impedance models for molten salt corrosion," Corrosion Science, vol. 43, no. 4, pp. 787-801, 2001.

[41] E. M. Sherif and S.-M. Park, "2-Amino-5-ethyl-1,3,4-thiadiazole as a corrosion inhibitor for copper in $3.0 \% \mathrm{NaCl}$ solutions," Corrosion Science, vol. 48, pp. 4065-4079, 2006.

[42] L. Hu, S. Zhang, W. Li, and B. Hou, "Electrochemical and thermodynamic investigation of diniconazole and triadimefon as corrosion inhibitors for copper in synthetic seawater," Corrosion Science, vol. 52, no. 9, pp. 2891-2896, 2010.

[43] E. S. M. Sherif, "Effects of 2-amino-5-(ethylthio)-1,3,4-thiadiazole on copper corrosion as a corrosion inhibitor in $3 \% \mathrm{NaCl}$ solutions," Applied Surface Science, vol. 252, no. 24, pp. 86158623, 2006.

[44] M. Cubillos, M. Sancy, J. Pavez et al., "Influence of 8-aminoquinoline on the corrosion behaviour of copper in $0.1 \mathrm{M} \mathrm{NaCl}$," Electrochimica Acta, vol. 55, pp. 2782-2792, 2010.

[45] S. M. Milić and M. M. Antonijević, "Some aspects of copper corrosion in presence of benzotriazole and chloride ions," Corrosion Science, vol. 51, pp. 28-34, 2009.

[46] E. M. Sherif, R. M. Erasmus, and J. D. Comins, "Corrosion of copper in aerated synthetic sea water solutions and its inhibition by 3-amino-1,2,4-triazole," Journal of Colloid and Interface Science, vol. 309, no. 2, pp. 470-477, 2007. 

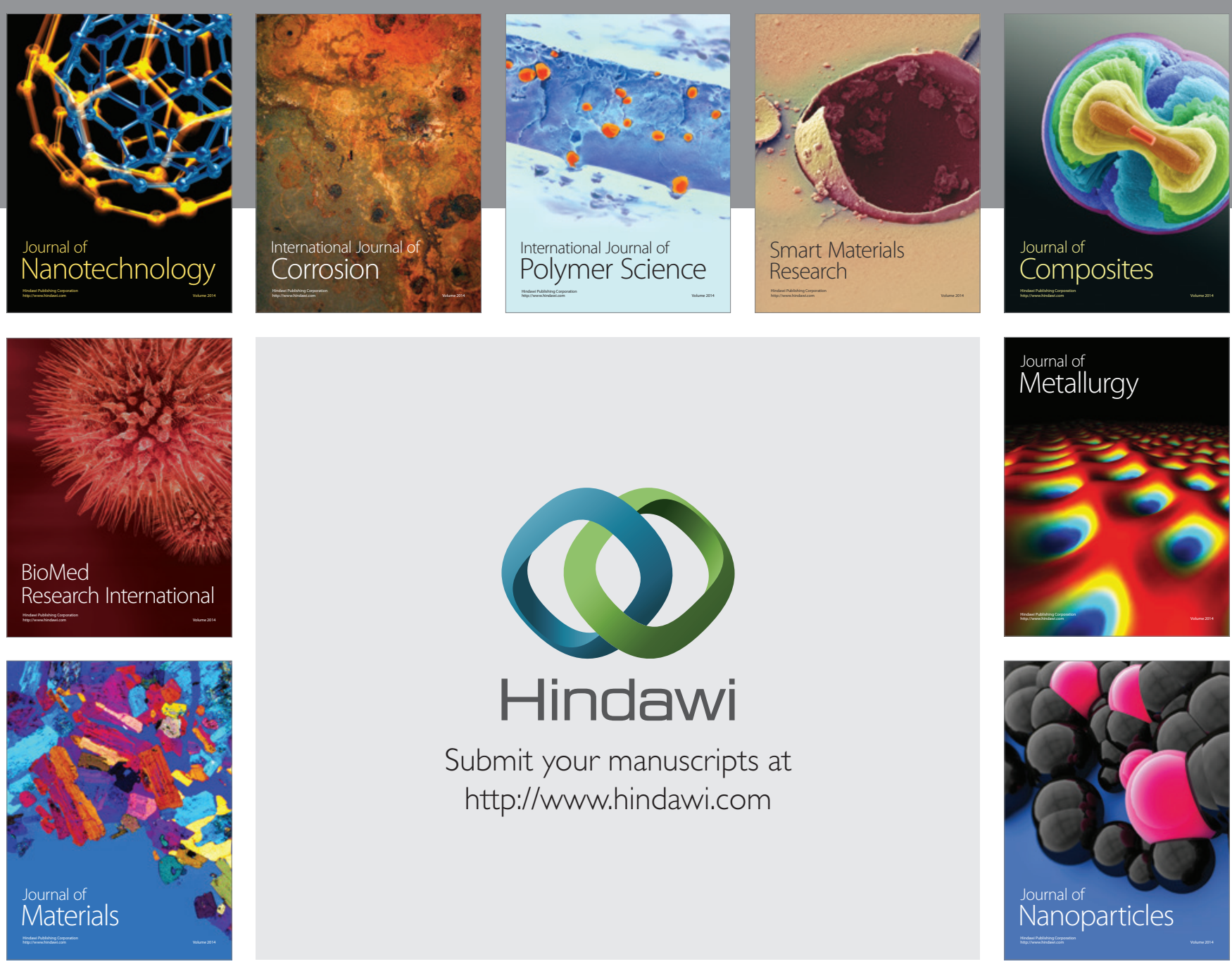

Submit your manuscripts at http://www.hindawi.com
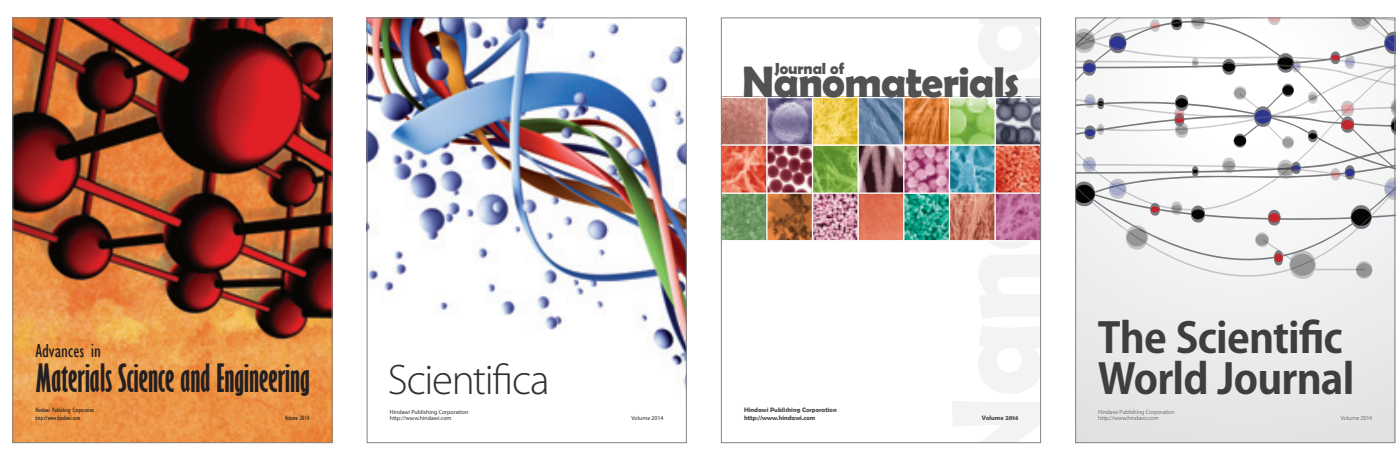

\section{The Scientific World Journal}
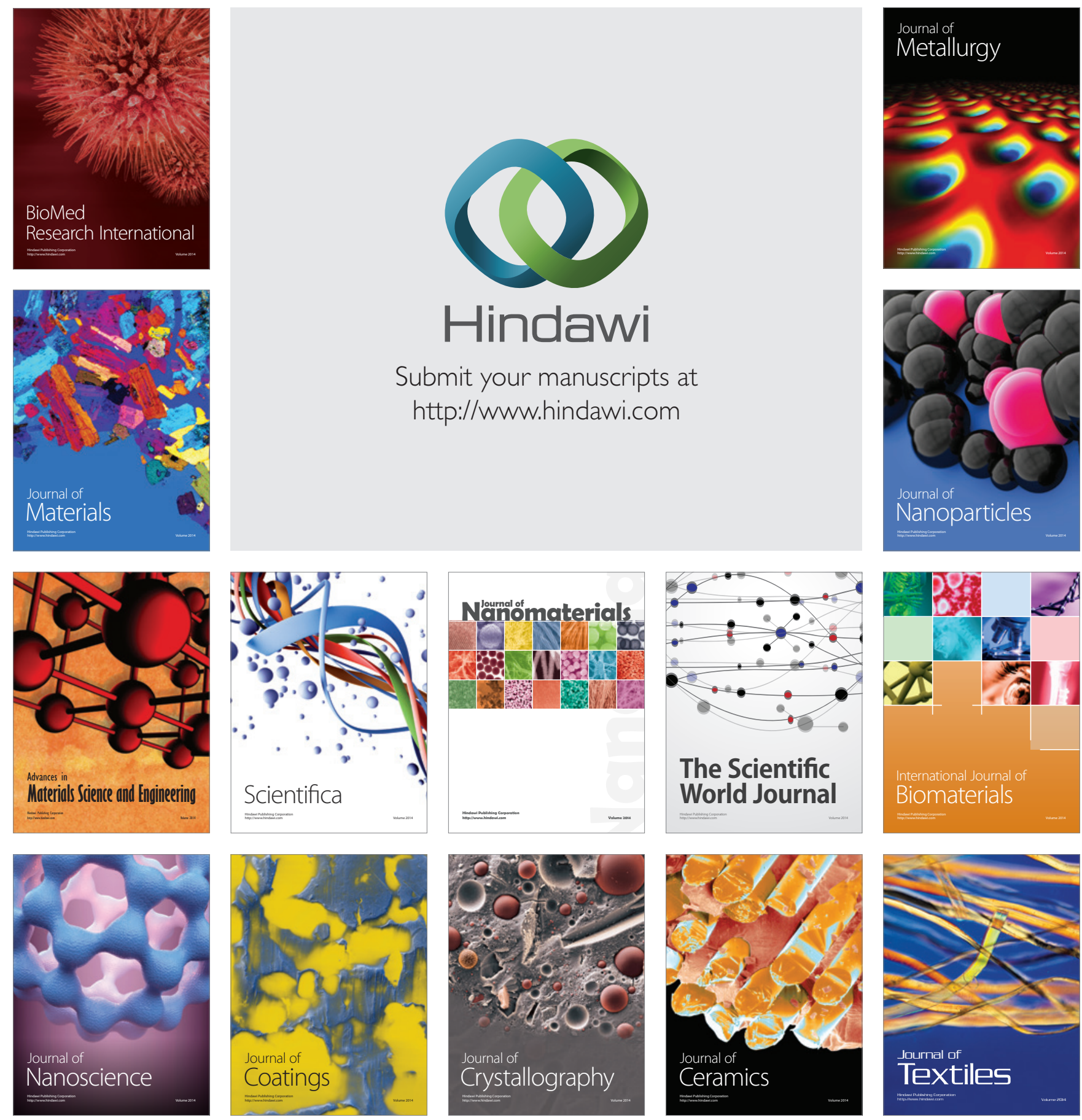